NASA/TM-1999-208909

\title{
Comparison of Techniques for Non-Intrusive Fuel Drop Size Measurements in a Subscale Gas Turbine Combustor
}

Michelle Zaller, Robert C. Anderson, and Yolanda R. Hicks Lewis Research Center, Cleveland, Ohio

Randy J. Locke

Dynacs Engineering Co., Inc., Brook Park, Ohio 
Since its founding, NASA has been dedicated to the advancement of aeronautics and space science. The NASA Scientific and Technical Information (STI) Program Office plays a key part in helping NASA maintain this important role.

The NASA STI Program Office is operated by Langley Research Center, the Lead Center for NASA's scientific and technical information. The NASA STI Program Office provides access to the NASA STI Database, the largest collection of aeronautical and space science STI in the world. The Program Office is also NASA's institutional mechanism for disseminating the results of its research and development activities. These results are published by NASA in the NASA STI Report Series, which includes the following report types:

- TECHNICAL PUBLICATION. Reports of completed research or a major significant phase of research that present the results of NASA programs and include extensive data or theoretical analysis. Includes compilations of significant scientific and technical data and information deemed to be of continuing reference value. NASA's counterpart of peerreviewed formal professional papers but has less stringent limitations on manuscript length and extent of graphic presentations.

- TECHNICAL MEMORANDUM. Scientific and technical findings that are preliminary or of specialized interest, e.g., quick release reports, working papers, and bibliographies that contain minimal annotation. Does not contain extensive analysis.

- CONTRACTOR REPORT. Scientific and technical findings by NASA-sponsored contractors and grantees.
- CONFERENCE PUBLICATION. Collected papers from scientific and technical conferences, symposia, seminars, or other meetings sponsored or cosponsored by NASA.

- SPECIAL PUBLICATION. Scientific, technical, or historical information from NASA programs, projects, and missions, often concerned with subjects having substantial public interest.

- TECHNICAL TRANSLATION. Englishlanguage translations of foreign scientific and technical material pertinent to NASA's mission.

Specialized services that complement the STI Program Office's diverse offerings include creating custom thesauri, building customized data bases, organizing and publishing research results ... even providing videos.

For more information about the NASA STI Program Office, see the following:

- Access the NASA STI Program Home Page at http://www.sti.nasa.gov

- E-mail your question via the Internet to help@sti.nasa.gov

- Fax your question to the NASA Access Help Desk at (301) 621-0134

- Telephone the NASA Access Help Desk at (301) 621-0390

- Write to:

NASA Access Help Desk

NASA Center for AeroSpace Information 7121 Standard Drive

Hanover, MD 21076 
NASA/TM-1999-208909

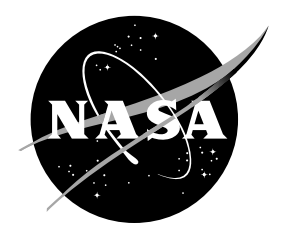

\section{Comparison of Techniques for Non-Intrusive Fuel Drop Size Measurements in a Subscale Gas Turbine Combustor}

Michelle Zaller, Robert C. Anderson, and Yolanda R. Hicks

Lewis Research Center, Cleveland, Ohio

Randy J. Locke

Dynacs Engineering Co., Inc., Brook Park, Ohio

Prepared for the

International Conference on Optical Technology and Image Processing in Fluid, Thermal, and Combustion Flow sponsored by the Visualization Society of Japan and the Society of Photo-Optical Instrumentation Engineers

Yokohama, Japan, December 6-10, 1998

National Aeronautics and

Space Administration

Lewis Research Center 
Trade names or manufacturers' names are used in this report for identification only. This usage does not constitute an official endorsement, either expressed or implied, by the National Aeronautics and Space Administration.

Available from

NASA Center for Aerospace Information 7121 Standard Drive

Hanover, MD 21076

Price Code: A03
National Technical Information Service 5285 Port Royal Road Springfield, VA 22100 Price Code: A03 


\title{
Comparison of Techniques for Non-Intrusive Fuel Drop Size Measurements in a Subscale Gas Turbine Combustor
}

\author{
Michelle Zaller", Randy J. Locke ${ }^{* *}$, Robert C. Anderson ${ }^{*}$, and Yolanda R. Hicks ${ }^{*}$ \\ "NASA Lewis Research Center, M.S. 77-1, 21000 Brookpark Road, Cleveland, OH 44135, U.S.A. \\ mzaller@lerc.nasa.gov, Robert.C.Anderson@lerc.nasa.gov, Yolanda.R.Hicks@lerc.nasa.gov \\ ** Dynacs Engineering Co., Inc., 2001 Aerospace Parkway, Brook Park, OH 44142, U.S.A. \\ Randy.J.Locke@lerc.nasa.gov
}

\begin{abstract}
In aviation gas turbine combustors, many factors, such as the degree and extent of fuel/air mixing and fuel vaporization achieved prior to combustion, influence the formation of undesirable pollutants. To assist in analyzing the extent of fuel/air mixing, flow visualization techniques have been used to interrogate the fuel distributions during subcomponent tests of lean-burning fuel injectors. Discrimination between liquid and vapor phases of the fuel was determined by comparing planar laser-induced fluorescence (PLIF) images, elastically-scattered light images, and phase/Doppler interferometer measurements. Estimates of Sauter mean diameters are made by ratioing PLIF and Mie scattered intensities for various sprays, and factors affecting the accuracy of these estimates are discussed. Mie calculations of absorption coefficients indicate that the fluorescence intensities of individual droplets are proportional to their surface areas, instead of their volumes, due to the high absorbance of the liquid fuel for the selected excitation wavelengths.
\end{abstract}

Keywords: Combustor, Fuel Sprays, Planar Laser-Induced Fluorescence (PLIF), Mie Scattering, Drop Size

\section{Introduction}

To reduce the impact of pollutant emissions from aircraft on the environment, and to meet proposed $\mathrm{NO}_{\mathrm{x}}$ emission regulations, reduction of pollutant emissions from gas turbine combustors is required. For a given pressure ratio and fuel/air ratio, pollutant production is influenced by the degree of fuel vaporization and mixing achieved prior to combustion. Due to the complexities of modeling and expense of conducting experiments on actual gas turbine combustors, some efforts have focussed on conducting tests at atmospheric pressure. Such tests have employed reacting and non-reacting fuel simulants, in attempts to recreate aspects of the actual two-phase flow, and to develop diagnostic techniques to measure parameters of interest.

Many researchers have characterized fuel concentrations, fuel/air ratios, and spray drop size distributions in swirl-stabilized spray flames and premixed, prevaporized subscale gas turbine combustors (e.g. Locke et al, 1995, Bulzan, 1995, McDonell et al, 1993, Locke et al, 1998). Phase Doppler interferometry (PDI) has been used to make spray drop size distribution and velocity measurements in spray flames, and to derive liquid mass flux from these parameters. Planar laser-induced fuel fluorescence has also been used to optically patternate sprays. Although PDI has become the standard technique for spray characterization, it is more difficult to align and timeconsuming to apply than planar imaging, especially in high-pressure combustors with limited optical access.

McDonell et al, 1995, used planar laser-induced fluorescence (PLIF) of fluorescein-doped methanol in a gas turbine swirl cup spray at ambient pressure to determine liquid phase fuel distributions. They obtained some agreement between fuel uniformity, as determined from images of the liquid fluorescence, and trends in $\mathrm{NO}_{\mathrm{x}}$ emissions. They also demonstrated qualitative agreement between volume distribution measurements from PLIF and PDI. From measurements of a monodisperse droplet stream, McDonell et al determined that the relationship between droplet volume and PLIF image intensity was linear for their setup.

Herpfer and Jeng, 1995, developed an innovative technique to simultaneously measure the drop sizes and velocities in burning gas turbine injector sprays using planar imaging. They were able to achieve good agreement between PDI and their planar technique in reacting sprays; however, their setup had some difficulty with low signal-to-noise in regions of high flame luminosity. Their calculations show that the intensity of the Mie-scattered light is proportional to the square of the droplet diameter for their collection angle, droplet size parameter, and liquid optical properties. 
More recently, Sankar et al, 1997, combined PLIF and planar Mie scattering by ratioing PLIF and elastically-scattered light intensities to determine spray volume-to-surface-area ratios. Sankar et al assumed that the accumulated PLIF image intensities were proportional to the summed droplet volumes, and the Mie signals, proportional to the sums of the drop cross-sectional areas. If the proportionality constants can be determined, then the ratios of these signals should equal:

$$
C \times \sum N_{i} d_{i}^{3} / \sum N_{i} d_{i}^{2}
$$

where $C$ is an experimentally determined constant, $N$ is the number of drops in the $i$ th size class, and $d$ is the representative diameter of that size class. This expression is proportional to the Sauter mean diameter (SMD). Sankar et al demonstrated good agreement between phase Doppler interferometry SMD measurements and ratios of PLIF/Mie scattered intensities in non-reacting sprays. We have applied this "optical patternator" technique to obtain planar measurements of fuel distributions in high pressure, reacting gas turbine combustor sprays.

\section{Setup}

Tests were conducted in the CE-5 Subcomponent Test Facility at the NASA Lewis Research Center for evaluation of advanced gas turbine injector concepts. Windowed combustor housings were used that allow optical access to reacting flows at pressures up to $2 \mathrm{MPa}(20 \mathrm{~atm})$, and flow temperatures up to $2000 \mathrm{~K}\left(3200{ }^{\circ} \mathrm{F}\right)$. Nonvitiated air is supplied to the test section at temperatures up to $840 \mathrm{~K}\left(1050{ }^{\circ} \mathrm{F}\right)$. The fuel injector is typically positioned so that the dome face is visible within the $3.8 \mathrm{~cm}(1.5$ ") (axial dimension) view of the windows. Flow path dimensions for the housing used in this study were $7.6 \times 7.6 \mathrm{~cm}(3 \times 3$ "). The flow path is formed by cast ceramic, which places a limitation on the maximum flame temperature. The inside surfaces of the windows, which are typically installed to be flush with the flow path formed by the ceramic liner, are cooled by a thin layer of gaseous nitrogen. JP-8 and Jet A fuels were used for the results presented here.

The layout of the test section, along with laser-based instrumentation, is shown in Figure 1. For the planar measurements, a Continuum Nd:YAG pumped dye laser with frequency doubling was used to generate approximately $18 \mathrm{~mJ} /$ pulse at $281.5 \mathrm{~nm}$. The laser output, formed into a sheet using a $3000 \mathrm{~mm}$ focal length cylindrical lens, enters the top of the windowed test section. By passing the laser sheet through acetone vapor in a quartz cell and recording fluorescence images, the focussed sheet thickness was determined to be $1200 \mu \mathrm{m}$ at $1 / \mathrm{e}^{2}$ width. To record images of fuel droplet scattering and fluorescence, a Princeton Instruments ICCD camera with a 384 x 576 element array was used. Two narrowband (10 nm FWHM) interference filters, one centered around 313 and another around $280 \mathrm{~nm}$, enabled selective detection of fuel fluorescence and Mie scattering, as well as rejection of background combustor radiation. For these tests, the laser was tuned away from any $\mathrm{OH}$ absorption lines, so the $313 \mathrm{~nm}$ filter detected broadband fluorescence of the jet fuel, which is believed to arise primarily from polyaromatic hydrocarbons (PAH), such as napthalene, present in the fuel (Hicks et al, 1997). A Phase/Doppler Particle Analyzer was also used to measure the size and velocity distributions of the fuel droplets for low inlet temperature conditions. Additional details of the experimental setup are given elsewhere (Hicks et al, 1997).

\section{Results}

The spray characteristics of two different types of injectors, with varying degrees of prevaporization, were analyzed in this study. The first flow field characterized was produced by a single element of a lean burning, premixing, prevaporizing injector. At the idle operating condition, the combustor inlet temperature was too low to completely vaporize all of the fuel before injection into the combustor. Since the injection velocities were high to prevent flashback for this premixed configuration, the flame stabilized several inches downstream of the injector dome face.

A comparison between PDI temporal measurements of Sauter Mean Diameter (SMD), and concentrationsensitive drop size measurements derived from intensity ratios of the PLIF and Mie planar images, is shown in Figure 2. Both data sets on the graph represent flow measurements acquired along a horizontal line, passing through the vertical center of the injector, and $6 \mathrm{~mm}$ downstream of the injector dome face. The images were binned by taking the averages of $4 \times 4$ blocks of pixels. Binning was necessary due to the unsteady nature of the flow, and also because the Mie and PLIF images were not acquired simultaneously. The trends between the PLIF/Mie ratios and the PDI drop size measurements are similar (Figure 2). The most notable difference is the peak in the PLIF/Mie ratio at $\mathrm{x}=15 \mathrm{~mm}$, which is not matched by the point SMD measurement. This degree of agreement is surprising, considering that the PLIF response is due to PAH in the vapor phase, as well as PAH in the liquid fuel droplets. It was postulated that the PLIF signals arising from the liquid and gaseous fluorescing phases happen to be similar, since higher vapor concentrations would be present in areas of higher liquid fuel drop number densities.

When cross-sections of the PLIF, Mie, and intensity ratios are compared (Figure 3), the PLIF and Mie plots resemble each other closely, except that the PLIF peaks appear slightly broader, probably due to signals 
arising from vaporized PAH. Number densities of drops as measured using PDI are also presented (Figure 3) for comparison with the Mie intensities. As would be expected, good agreement is seen between the plots of PDI number densities, and averaged Mie intensities, since both are related to the droplet concentrations.

Results from a second injector configuration, for which the fuel was not prevaporized, are presented in Figure 4. This injector produced a hollow-cone spray, so PDI measurements were only obtained in fuel spray regions of higher number density, away from the injector centerline. Although PDI measurements were attempted across the entire diameter of the spray, the data rate was nearly zero for the negative $\mathrm{x}$ locations. This was attributed to multiple scattering effects induced by high number densities of very small droplets, which resulted in extinction of the scattered PDI signal. The agreement in this case is not conclusive, but it could be argued that the relatively sparse PDI data are related to the PLIF/Mie ratio values.

As was the case with the prevaporized injector, good agreement is seen between the number density of drops as reported by the PDI, and the Mie intensities (Figure 5). Since the trends in the PLIF and Mie plots are similar, when the PLIF is divided by the Mie signal, the highest ratio values occur just outside of the Mie peaks. This is somewhat disturbing, since it indicates that the highest PLIF/Mie values arise from vaporized fuel, instead of liquid droplets.

To illustrate this problem, slices of the PLIF and Mie signals, for different axial distances downstream of the injector, are shown in Figure 6. Since the PLIF and Mie peak intensities are similar, when the image ratios are taken, the peaks are replaced by gaps, generating an annular shape for this hollow-cone spray (Figure 6). Although the PLIF and Mie images provide fantastic information about locations, relative concentrations, and extent of liquid and gas phase fuel distributions in these complex, high pressure, and high number density reacting spray flow fields, the image data are difficult to quantify. It appears that additional efforts will be required to resolve the difficulties introduced by PLIF detection of PAH in both liquid and gas phase.

To help resolve this difficulty with the fuel PLIF signals, the feasibility of using PLIF/Mie ratios to determine spray drop sizes for our setup was analyzed using a far-field Mie scattering code from Valley Scientific, Inc. The scattered light intensities were computed using a real refractive index, $\mathrm{n}$, of 1.4 , and a wide range of imaginary refractive indices, $\mathrm{k}$. Other setup parameters included a detection angle of $90^{\circ}$, and perpendicularly polarized incident light, with $\lambda=.2815 \mu \mathrm{m}$. Computations were performed for drop diameters from 1 to $200 \mu \mathrm{m}$. Results are plotted in Figure 7 as a function of $x^{2}$ (where $\left.x=\pi d / \lambda\right)$. For $k$ larger than about .01 , there is a linear relationship between the square of the droplet diameter and scattered intensity, even without performing any averaging over the receiving lens aperture. Absorbance data (Hicks et al, 1997) were used to calculate an imaginary refractive index of .045 at $281 \mathrm{~nm}$ for JP-5, indicating that the Mie signals were proportional to the squared droplet diameters for our experiment.

Absorption efficiencies, Qabs, are plotted in Figure 8 for the same parameters $(n=1.4, \lambda=.2815 \mu \mathrm{m}$, $1<\mathrm{d}<200 \mu \mathrm{m}$ ). If the fluorescence induced in the droplet is isotropic, then the absorption efficiency will indicate the relationship between droplet size parameter and fluorescence signal. Since $\mathrm{Q}_{\mathrm{abs}}$ is normalized by the droplet cross-sectional area, $\pi \mathrm{d}^{2} / 4$, then a linear relationship between droplet size and $\mathrm{Q}_{\text {abs }}$ indicates that the drop fluorescence intensities are proportional to $\mathrm{d}^{3}$. Unfortunately, it can be seen that only minimally absorbing drops exhibit absorption efficiencies that are linearly proportional to drop size (Figure 8). For $\mathrm{k}$ greater than .0001, the relationship between drop volume and fluorescence signal will not be linear for our droplet size range. In fact, for $\mathrm{k}>.01$, the drop fluorescence intensity will be linearly proportional to the drop cross-sectional area, instead of its volume. This implies that for the PLIF/Mie ratioing technique to be successfully applied, the imaginary refractive index for the PLIF measurements should be .0001 or smaller. However, for fluorescence to occur, the liquid molecules must be absorbing, which implies larger k values. Such small values of $\mathrm{k}$ are also not optimal for Miescattering measurements at $90^{\circ}$ collection angle, although using parallel polarization, an alternative collection angle, and/or a sufficiently large aperture lens, would damp out intensity oscillations. Different wavelengths could be used for the elastically-scattered and PLIF measurements that exhibited high absorption for the Mie, and less absorption for the PLIF. Since the imaginary refractive index of JP-5 is about .045 for the wavelength used in our tests, the PLIF signal responses were proportional to the squared droplet diameters, instead of the droplet volumes. This would explain why our PLIF and Mie signals nearly cancelled each other out. If our PLIF and Mie signals were both proportional to the drop cross-sectional areas, then their ratios should have been a constant: if not for the vapor fuel response of the PLIF, our signal ratios would have been nothing but noise.

Rotunno et al, 1990, claimed a linear relationship between (drop diameter) ${ }^{3}$ and fluorescence intensities for droplets with an optical density of 0.2 or less. They considered a maximum drop size parameter of 530 for their exciplex fluorescence experiment. An optical density of 0.2 corresponds to an imaginary refractive index of .0002 at their wavelength of $355 \mathrm{~nm}$. This agrees with the computations presented in Figure 8, since the $\mathrm{k}=.0002$ line is fairly straight for size parameters from 10 to 530, whereas curvature is visible in the slightly more absorbing $\mathrm{k}=.0005$ data over the same size range. 
The differences in the internal intensities for minimally and highly absorbing drops were computed using Mie scattering code for spheres published by Barber and Hill, 1990. Although these internal intensities are for the incident wavelength only, it is assumed that the fluorescence signal will be proportional to the intensity of the exciting laser light. Cross-sections of the log of the Mie intensities are plotted in Figures 9 and 10 for size parameters of $x=10$ and $x=100$. The incident linearly polarized wave propagates from the bottom to the top in these figures. Figure 9 shows the cross-section intensities for all intensity values within the drop radii. The same data are plotted in Figure 10, except that the ranges of contour values were limited to 4 orders of magnitude. A low $\mathrm{k}$ value of .0001 was used in the computations on the left side, and our estimated $\mathrm{k}$ value (.045 for JP-5 at $281 \mathrm{~nm})$ in the plots on the right. For very tiny drops $(\mathrm{x}=10)$, the Mie intensities are similar for both $\mathrm{k}$ values (Figures 9a and 9b). Light passing through the droplet is internally reflected multiple times to produce an interference pattern, with a focus opposite the incident beam. However, if the drop sizes are increased to $\mathrm{x}=100$, it can be seen that the highly absorbing drop (Figure 9d) has most of the intensity absorbed near the droplet surface. In the less absorbing case (Figure 9c), the interfering internally reflected light, as well as the focus at the top of the plot, can be seen.

When the same results are plotted, except using contour values that are limited to four orders of magnitude, the similarities between the $\mathrm{x}=10$ droplets for $\mathrm{k}=.0001$ and $\mathrm{k}=.045$ are still apparent (Figure 10a and 10b). However, for a size parameter of $\mathrm{x}=100$, the difference between intensity fields for the low and high imaginary refractive indices is emphasized (Figures 10c and 10d). Despite the relatively small drop diameter of $\mathrm{d}=9$ microns, all of the light incident on the $\mathrm{k}=.045$ drop is absorbed near the surface, without passing through the drop to form any interference pattern, or foci. This explains why the highly absorbing drops $(\mathrm{k}=.045)$ have a fluorescence signal proportional to their surface areas.

Results by McDonell et al, 1995, of droplet fluorescence intensities qualitatively agree with the above analytical results. For their tests, the relationship between drop fluorescence intensities and volumes was linear for the sizes they were able to produce with a monodisperse drop generator (approximately 60-220 microns). The fluorescence intensity for a single droplet illuminated by a laser sheet exhibited the same high intensity region illustrated by plots of the cross-section calculations of uniformly illuminated, minimally absorbing drops in Figure 10. Their results are in agreement with the Mie calculations presented here, for which low liquid absorbances allowed the laser light to pass through the drops with little attenuation, and generated the expected linear relationship between fluorescence intensity and droplet volume.

\section{Conclusions}

Comparisons between PDI measurements and PLIF/Mie images were conducted on high pressure gas turbine combustor flow fields. Although some similarities between the drop sizes were apparent for tests on a prevaporizing injector, conclusive agreement between PLIF/Mie and PDI Sauter mean diameters was not demonstrated on a hollow cone spray with direct fuel injection. It appears that the Mie and PLIF signals were related to the drop number densities, which makes the combination of these techniques invaluable for rapid determination of liquid and vaporized fuel distribution over large regions of the combustor.

Mie scattering calculations indicate that although the elastically-scattered light intensities are proportional to the drop cross-sectional areas, the PLIF response for our laser wavelength and fuel imaginary refractive index did not produce a signal that is proportional to the droplet volumes. Additional work is required to determine the error introduced by the PLIF response to gaseous and liquid phase fuel, since the liquid phase response may not be linear, or may even be non-existent, and the gas phase measurements need to be accounted for before the PLIF/Mie ratio is computed. Although these analyses are preliminary, they have been invaluable in determining the sensitivity of the derived values to such factors as laser wavelength, laser power fluctuations, flow field oscillations, and beam polarization direction. Future work will include attempts to elicit droplet fluorescence at wavelengths for which the fuel is less absorbing, which would make the fluorescence signal proportional to the droplet volumes. We also expect to study the differences in extent and response of the fluorescence signals arising from both gas and liquid phase fuel, Mie-scattered (liquid phase) light for information about fuel/air mixing, and the relationship between fuel/air mixing and combustor emissions.

\section{References}

Barber, P.W., and Hill, S.C., Light Scattering by Particles: Computational Methods. World Scientific Publishing Co., Singapore, 1990.

Bulzan, D.L., Structure of a Swirl-Stabilized Combusting Spray, J. Prop. Power, Vol. 11, No. 6, 1995, pp. 10931102.

Herpfer, D.C., and Jeng, S.M., Streaked Particle Image Velocimetry and Sizing in Burning and Non-Burning Sprays. 33 ${ }^{\text {rd }}$ Aerospace Sciences Meeting and Exhibit, AIAA Paper No. 95-0141, Reno, NV, Jan. 1995. 
Hicks, Y.R., Locke, R.J., Anderson, R.C., Zaller, M., and Schock, H.J., Imaging Fluorescent Combustion Species in Gas Turbine Flame Tubes: On Complexities in Real Systems. $33^{\text {rd }}$ AIAA/ASME/SAE/ASEE Joint Propulsion Conference and Exhibit, AIAA Paper No. 97-2837, Seattle, WA, July 1997.

Locke, R.J., Hicks, Y.R., Anderson, R.C., Chun, K.S., Ockunzzi, K.A., and North, G.L., Two-Dimensional Imaging of $\mathrm{OH}$ in a Lean Burning High Pressure Combustor. $33^{\text {rd }}$ Aerospace Sciences Meeting and Exhibit, AIAA Paper No. 95-0173, Reno, NV, Jan. 1995.

Locke, R.J., Hicks, Y.R., Anderson, R.C., and Zaller, M.M., Fuel Injector Patternation Evaluation in Advanced Liquid-Fueled, High Pressure, Gas Turbine Combustors, Using Nonintrusive Optical Diagnostic Techniques. NASA TM-1998-206292, February 1998.

McDonell, V.G., Adachi, M., and Samuelsen, G.S., Structure of Reacting and Nonreacting, Nonswirling, AirAssisted Sprays, Part II: Drop Behavior. Atomization and Sprays, Vol. 3, No. 4, 1993, pp. 411-436.

McDonell, V., Lee, S., and Samuelsen, S., Interpretation of Spray Behavior in Complex Aerodynamic Flows Using Phase Doppler Interferometry and Planar Liquid Laser Induced Fluorescence. Proc. SPIE, Optical Techniques in Fluid, Thermal, and Combustion Flow, S. Cha and J. Trolinger, eds., Vol. 2546, Sept. 1995, pp. 530-539.

Rotunno, A.A., Winter, M., Dobbs, G.M., and Melton, L.A., Direct Calibration Procedures for Exciplex-Based Vapor/Liquid Visualization of Fuel Sprays. Combust. Sci. and Tech., Vol. 71, 1990, pp. 247-261.

Sankar, S.V., Maher, K.E., Robart, D.M., and Bachalo, W.D., Rapid Characterization of Fuel Atomizers Using an Optical Patternator. Presented at ASME Asia '97, Singapore, Oct. 1997.

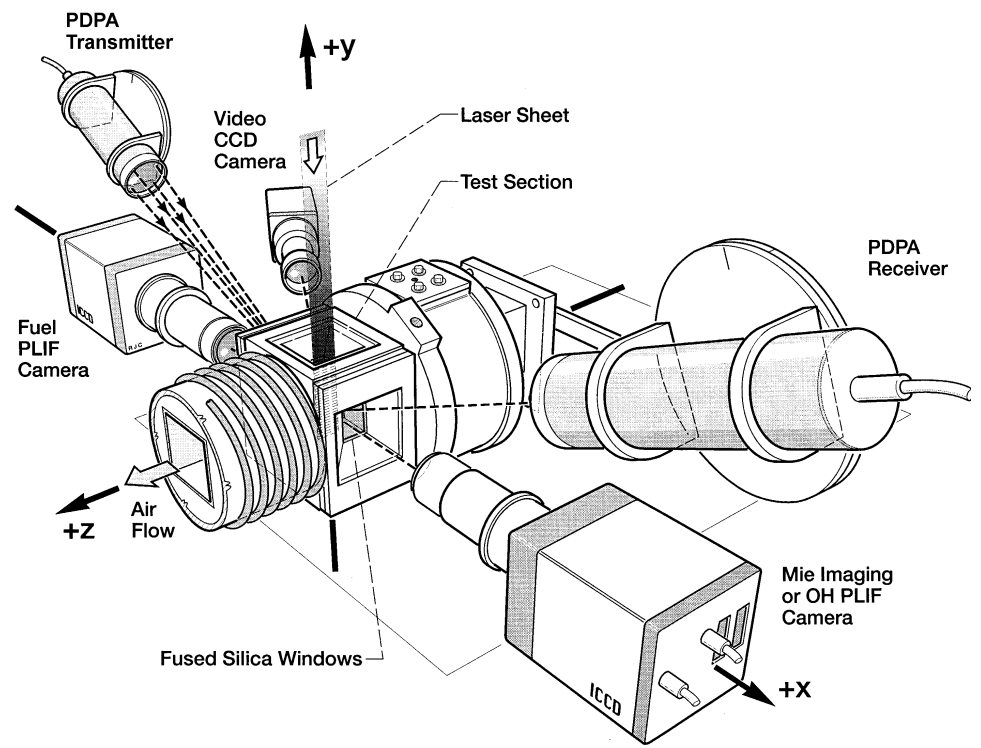

Figure 1. Optical instrumentation layout around windowed combustor.

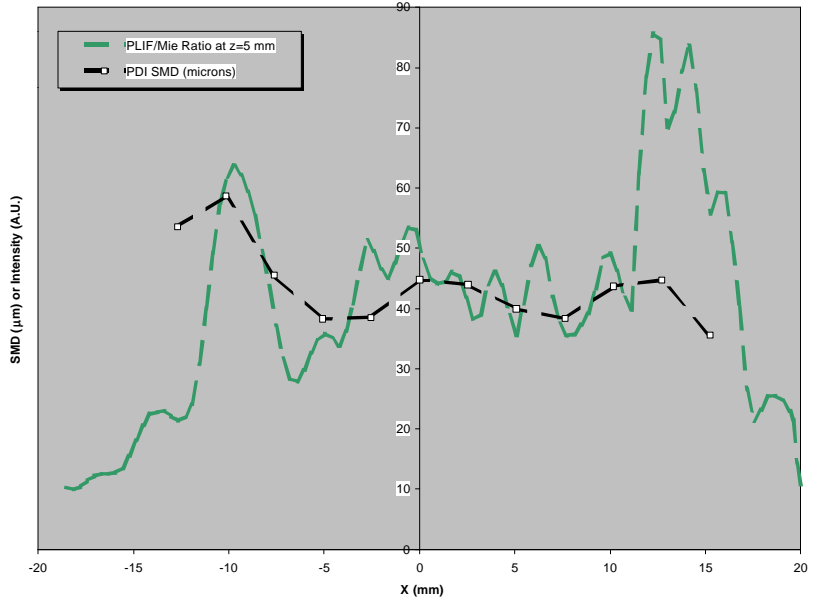

Figure 2. SMD comparison of PDI and PLIF/Mie ratio for $>95 \%$ prevaporized spray.

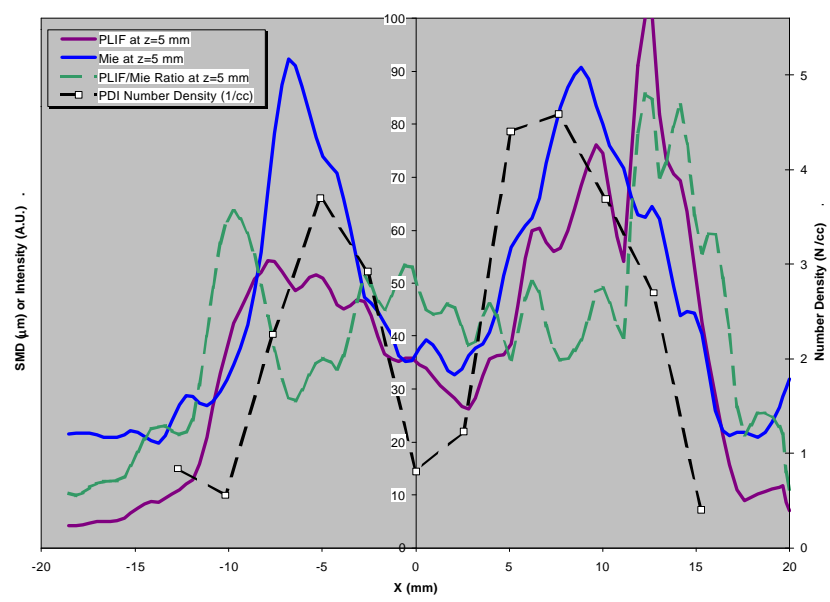

Figure 3. PLIF, Mie, and PLIF/Mie ratios for prevaporized injector, with PDI number densities for comparison with scaled Mie. 


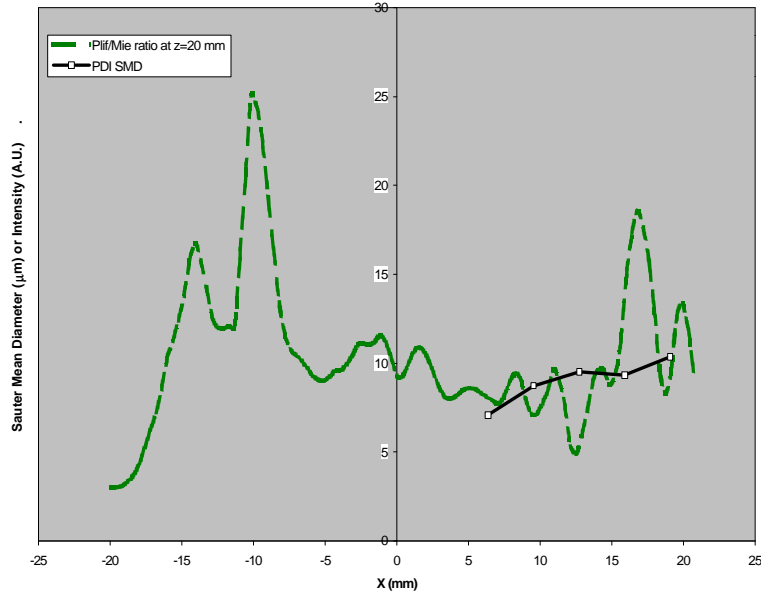

Figure 4. SMD comparison of PDI and PLIF/Mie ratio for hollow cone spray.

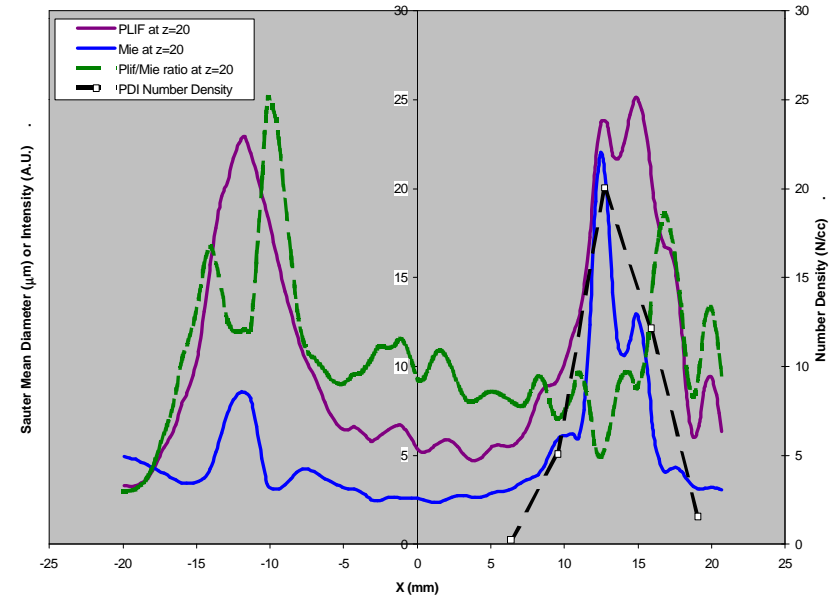

Figure 5. PLIF, Mie, and PLIF/Mie ratios for hollow cone spray injector, with PDI number densities for comparison with scaled Mie.
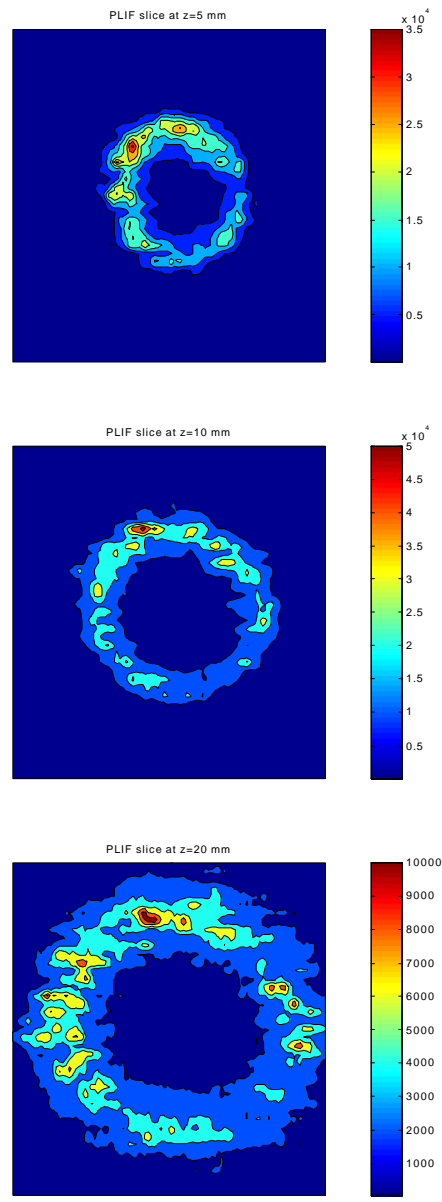
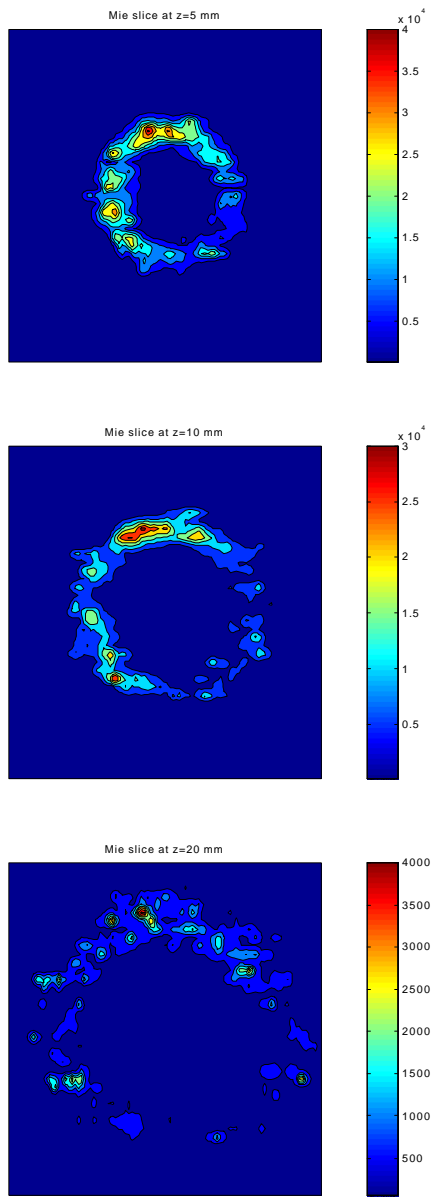
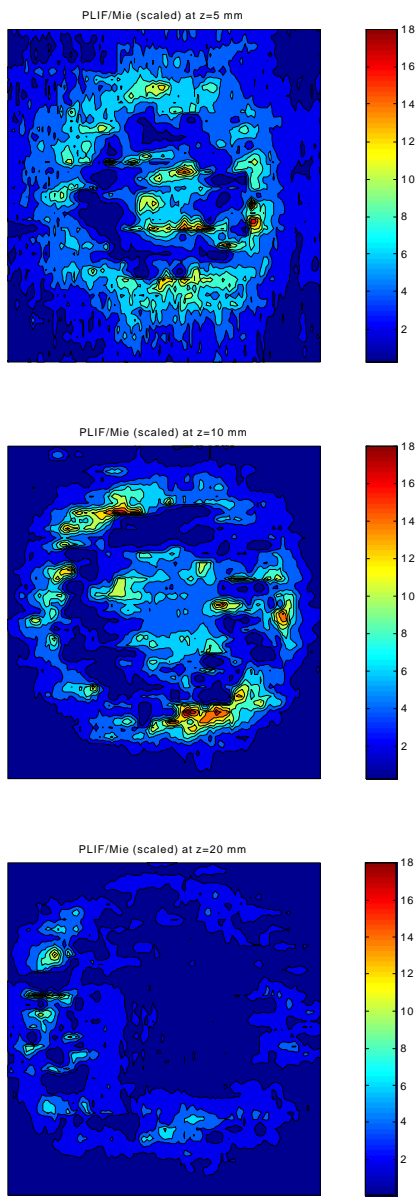

Figure 6. Hollow cone spray PLIF, Mie, and ratio cross-sections 5, 10, and $20 \mathrm{~mm}$ downstream of the dome. 


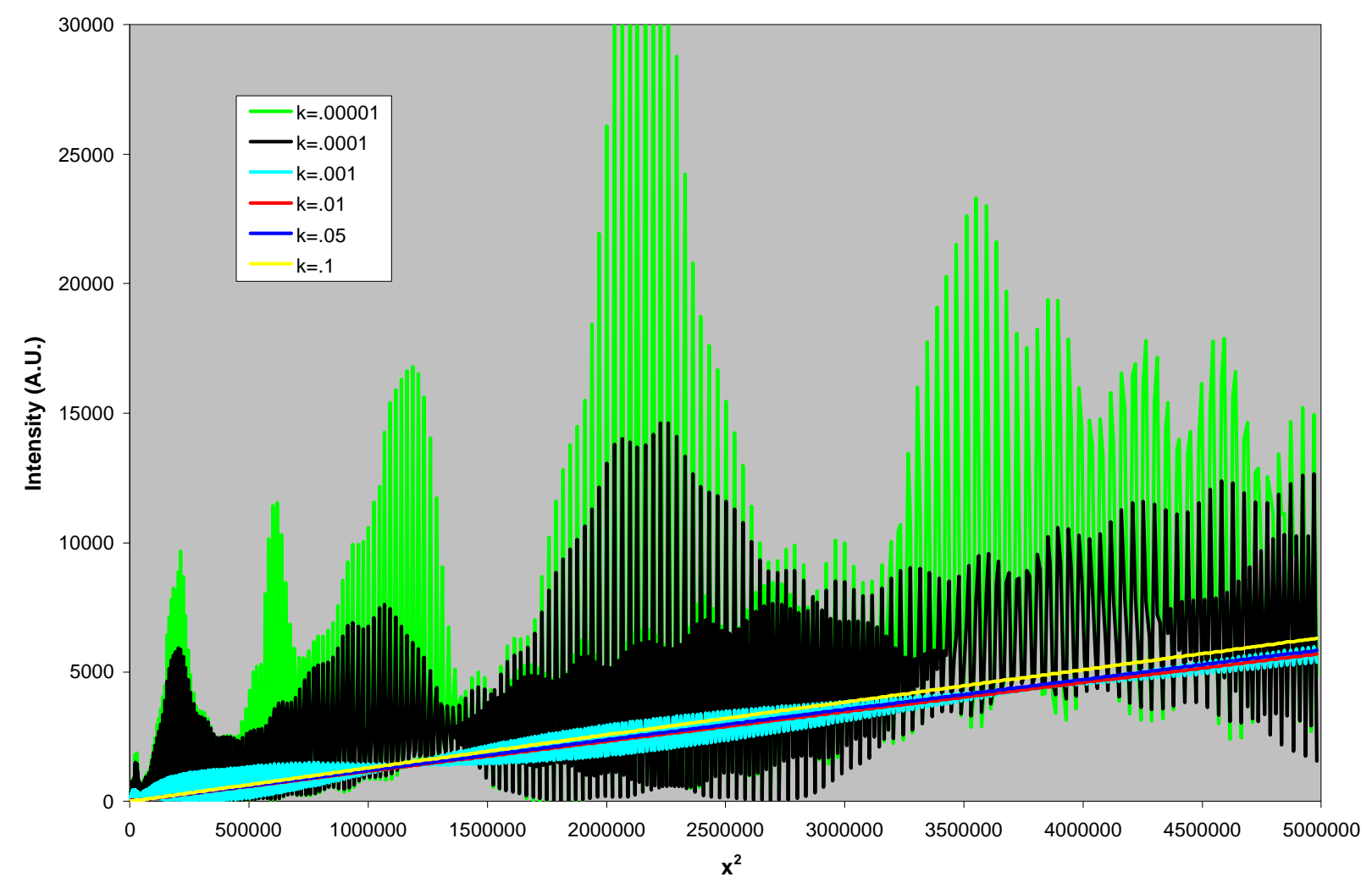

Figure 7. Mie-scattered intensities for various imaginary refractive indices. $\mathrm{n}=1.4, \theta=90^{\circ}, \lambda=.2815 \mu \mathrm{m}$.

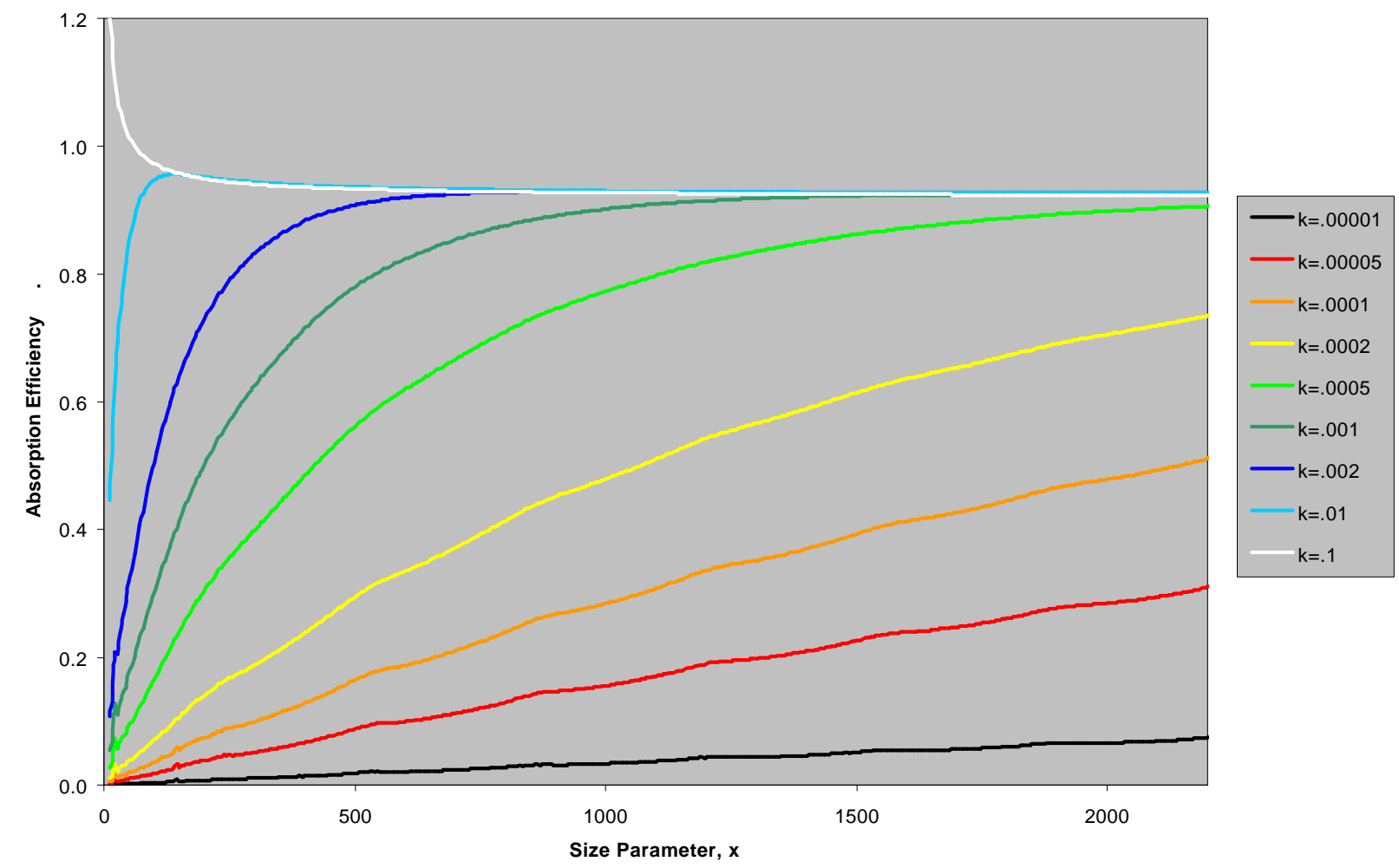

Figure 8. Absorption efficiencies for various imaginary refractive indices. $\mathrm{n}=1.4, \lambda=.2815 \mu \mathrm{m}$. 


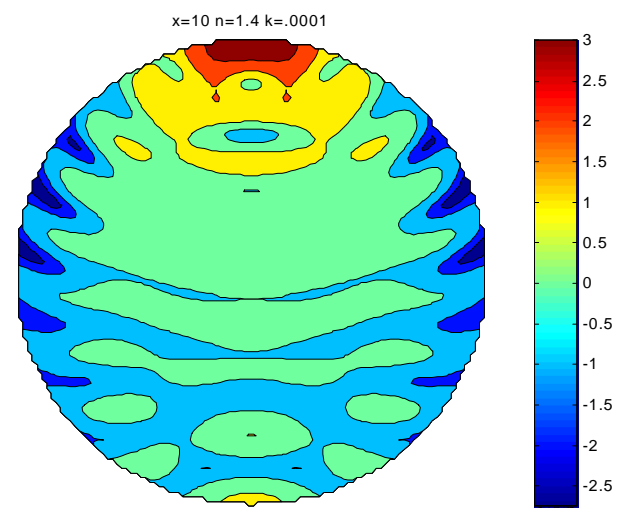

a. $\mathrm{d}=.9$ microns, low absorption.

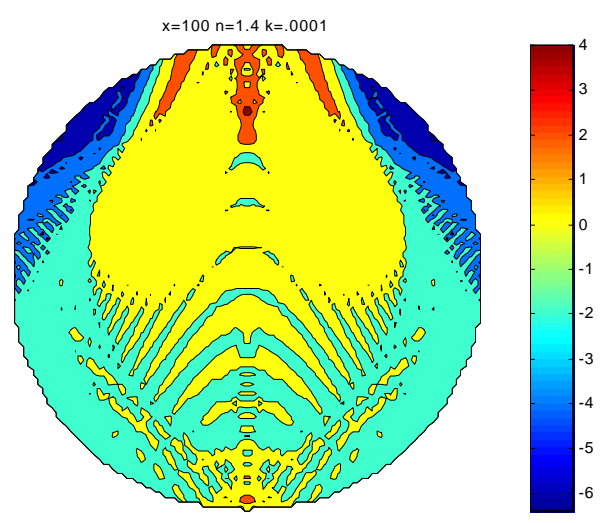

c. $\mathrm{d}=9$ microns, low absorption.

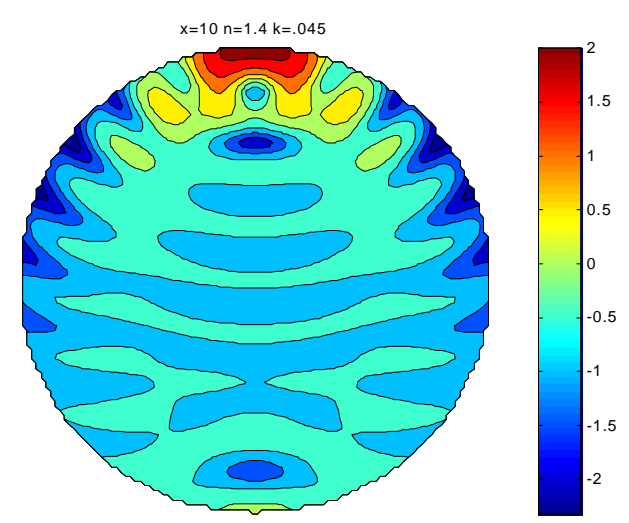

b. $d=.9$ microns, highly absorbing.

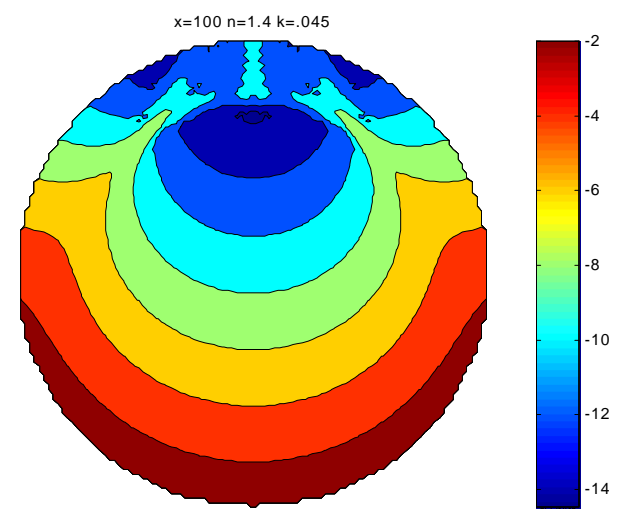

d. $d=9$ microns, highly absorbing.

Figure 9. Contour plots of log of cross-section Mie intensities for two sizes and absorbances.

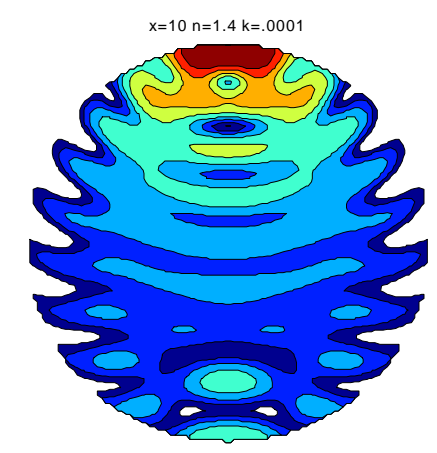

a. $\mathrm{d}=.9$ microns, low absorption.

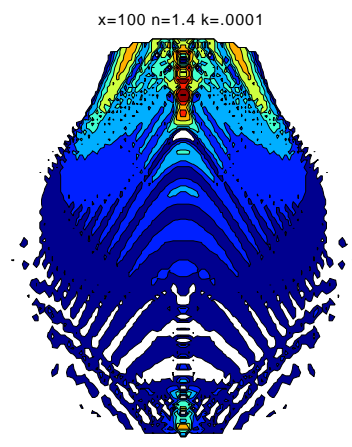

c. $\mathrm{d}=9$ microns, low absorption.
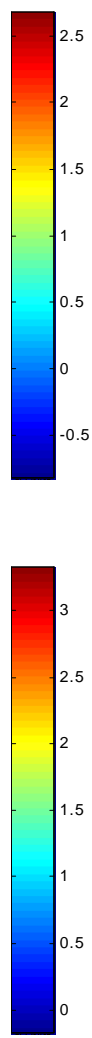

Figure 10. Contour plots of log of cross-section Mie intensities for two sizes and absorbances, for limited intensity ranges. 
Public reporting burden for this collection of information is estimated to average 1 hour per response, including the time for reviewing instructions, searching existing data sources, gathering and maintaining the data needed, and completing and reviewing the collection of information. Send comments regarding this burden estimate or any other aspect of this collection of information, including suggestions for reducing this burden, to Washington Headquarters Services, Directorate for Information Operations and Reports, 1215 Jefferson Davis Highway, Suite 1204, Arlington, VA 22202-4302, and to the Office of Management and Budget, Paperwork Reduction Project (0704-0188), Washington, DC 20503.

\begin{tabular}{|l|l|l}
\hline 1. AGENCY USE ONLY (Leave blank) & $\begin{array}{c}\text { 2. REPORT DATE } \\
\text { February } 1999\end{array}$ & $\begin{array}{r}\text { 3. REPORT TYPE AND DATES COVERED } \\
\text { Technical Memorandum }\end{array}$ \\
\hline
\end{tabular}

\section{TITLE AND SUBTITLE}

Comparison of Techniques for Non-Intrusive Fuel Drop Size Measurements in a Subscale Gas Turbine Combustor

6. AUTHOR(S)

Michelle Zaller, Randy J. Locke, Robert C. Anderson, and Yolanda R. Hicks

\section{FUNDING NUMBERS}

WU-537-05-20-00

\section{PERFORMING ORGANIZATION NAME(S) AND ADDRESS(ES)}

National Aeronautics and Space Administration

Lewis Research Center

Cleveland, Ohio 44135-3191

8. PERFORMING ORGANIZATION REPORT NUMBER

E-11523

\section{SPONSORING/MONITORING AGENCY NAME(S) AND ADDRESS(ES)}

National Aeronautics and Space Administration

Washington, DC 20546-0001

10. SPONSORING/MONITORING AGENCY REPORT NUMBER

NASA TM-1999-208909

\section{SUPPLEMENTARY NOTES}

Prepared for the International Conference on Optical Technology and Image Processing in Fluid, Thermal, and Combustion Flow sponsored by the Visualization Society of Japan and the Society of Photo-Optical Instrumentation Engineers, Yokohama, Japan, December 6-10, 1998. Michelle Zaller, Robert C. Anderson, and Yolanda R. Hicks, NASA Lewis Research Center; Randy J. Locke, Dynacs Engineering Co., Inc., 2001 Aerospace Parkway, Brook Park, Ohio 44142. Responsible person, Michelle Zaller, organization code 5520, (216) 433-5992.

12a. DISTRIBUTION/AVAILABILITY STATEMENT

\section{2b. DISTRIBUTION CODE}

Unclassified - Unlimited

Subject Categories: 35 and 07

Distribution: Nonstandard

This publication is available from the NASA Center for AeroSpace Information, (301) 621-0390.

\section{ABSTRACT (Maximum 200 words)}

In aviation gas turbine combustors, many factors, such as the degree and extent of fuel/air mixing and fuel vaporization achieved prior to combustion, influence the formation of undesirable pollutants. To assist in analyzing the extent of fuel/ air mixing, flow visualization techniques have been used to interrogate the fuel distributions during subcomponent tests of lean-burning fuel injectors. Discrimination between liquid and vapor phases of the fuel was determined by comparing planar laser-induced fluorescence (PLIF) images, elastically-scattered light images, and phase/Doppler interferometer measurements. Estimates of Sauter mean diameters are made by ratioing PLIF and Mie scattered intensities for various sprays, and factors affecting the accuracy of these estimates are discussed. Mie calculations of absorption coefficients indicate that the fluorescence intensities of individual droplets are proportional to their surface areas, instead of their volumes, due to the high absorbance of the liquid fuel for the selected excitation wavelengths.

\section{SUBJECT TERMS}

Imaging techniques; Fuel sprays; Combustion; Laser induced fluorescence

17. SECURITY CLASSIFICATION
OF REPORT
Unclassified

\begin{tabular}{|c|c|}
\hline $\begin{array}{c}\text { 18. SECURITY CLASSIFICATION } \\
\text { OF THIS PAGE } \\
\text { Unclassified }\end{array}$ & $\begin{array}{c}\text { 19. SECURITY CLASSIFICATION } \\
\text { OF ABSTRACT } \\
\text { Unclassified }\end{array}$ \\
\hline
\end{tabular}

Standard Form 298 (Rev. 2-89)

Prescribed by ANSI Std. Z39-18 298-102 